Tetrahedron Letters

journal homepage: www.elsevier.com

\title{
Pd-Catalyzed Asymmetric Allylic Amination with BOP Ligands and Its Applications to the Synthesis of Fused polycyclic Alkaloids
}

\author{
Yang Zang and Iwao Ojima* \\ Department of Chemistry, Stony Brook University, Stony Brook, New York 11794-3400, United States \\ Dedicated to late Professor Harry H. Wasserman for his outstanding achievements and fond memories
}

\section{ARTICLE INFO}

Article history:

Received

Received in revised form

Accepted

Available online

Keywords:

Asymmetric Allylic Amination

BOP Ligands

Palladium Catalysts

Alkaloids

Amaryllidaceae family consists of about 85 genera and 1,100 species. ${ }^{1}$ To date, nearly 500 structurally diverse alkaloids have been isolated from these plants. ${ }^{1}$ Some representative alkaloids are shown in Figure 1. Most of them exhibit various biological activities. $^{2-12}$ Crinine-type alkaloids have been shown to be active against rat hepatoma cells. ${ }^{4}$ A preliminary structure-activity study revealed that a free secondary hydroxyl group at $\mathrm{C} 11$ and an $\alpha-$ 5,10 b-ethano bridge were essential for their biological activity. ${ }^{2,3}$ Lycorine was found to be a potential therapeutic agent against acute promyelocytic leukemia. ${ }^{4}$ Montanine and pancratistatin exhibited antiviral, anxiolytic, antidepressive, and anticonvulsive activities..$^{5-12}$

Because of their diverse biological activities and intriguing structures, many chemical syntheses of these alkaloids have been reported. ${ }^{13-24}$ The first total synthesis of racemic pancracine was accomplished by Overman (Scheme 1A). ${ }^{13}$ The Overman's intermediate 3 bearing a 5,11-methanomorphanthridine skeleton was constructed through a tandem aza-Cope rearrangement/ Mannich cyclization of $\mathbf{1}$, followed by a Pictect-Spengler cyclization of $2 .{ }^{13}$ This intermediate $\mathbf{3}$ was also used in the asymmetric total synthesis of (-)-pancracine by Anada. ${ }^{14}$ Weinreb reported the first enantioselective total synthesis of (-)-montanine employing an intramolecular concerted allenylsilane imino ene cyclization of $\mathbf{4}$ and the subsequent intramolecular Heck reaction of 5 in the pivotal steps (Scheme 1B). ${ }^{15}$ Since certain polycyclic alkaloids, such as $\mathbf{2}, \mathbf{3}, \mathbf{5}$ and $\mathbf{6}$, serve as key intermediates for the total synthesis of amarylidaceae alkaloids, we envisioned potential

* Corresponding author. e-mail: iwao.ojima@stonybrook.edu utilities of similar polycyclic alkaloids bearing piperonylamine skeleton with excellent enantiopurity (Scheme 2).

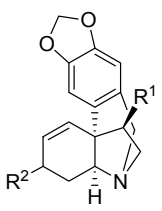

$\mathrm{R}^{1}=\mathrm{H}, \mathrm{R}^{2}=\alpha-\mathrm{OH}$ crinine $\mathrm{R}^{1}=\mathrm{OH}, \mathrm{R}^{2}=\alpha-\mathrm{OMe}$ crinamine $R^{1}=O H, R^{2}=\beta$-OMe haemanthamine $R^{1}=H, R^{2}=O H, R^{3}=H, R^{4}=O H$ brunsvigine

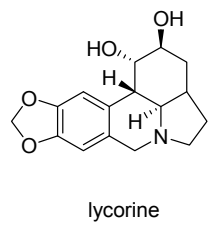

Figure 1. Amarylidaceae alkaloids

We have been developing a library of novel chiral biphenol-based monodentate phosphite and phosphoramidite ligands, ${ }^{25-34}$ as well as bidentate diphosphinite ligands (BOP ligands) for a variety of catalytic asymmetric reactions. ${ }^{31,32,24}$ These ligands are easy to prepare and fine-tunable through modification of the groups at the 3,3'-positions and the substituents attached to the phosphorous atoms. Our BOP ligands have exhibited excellent efficiency in Pdcatalyzed asymmetric allylic amination ${ }^{31,32}$ (AAA) and 
etherification $^{34}$ (AAE) reactions (up to $97 \%$ ee). Accordingly, we examined the efficiency of our BOP ligands in the AAA reaction of piperonylamides $\mathbf{8}$ and cyclohexenylcarbonates $\mathbf{7}$ to give cyclohexenylpiperonylamides $\mathbf{1 0}$ (Scheme 2). We describe here excellent efficiency of the optimized BOP ligand for this AAA reaction and versatility of $\mathbf{1 0}$ with high enantiopuiry for the synthesis of fused polycylic alkaloids, which would serve as advanced intermediates for the total synthesis of complex amarylidaceae alkaloids and their analogs.

(A) Overman's total synthesis of pancracine
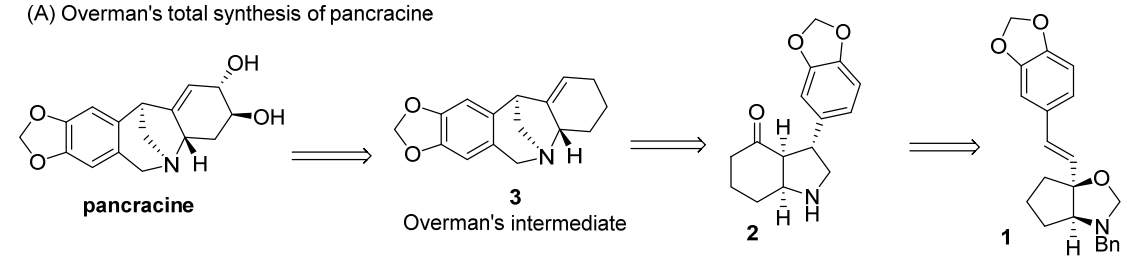

(B) Weinreb's total synthesis of (-)-montanine

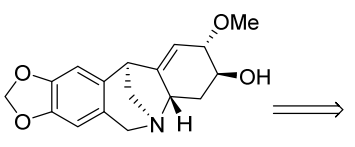

$(-)-$ montanine

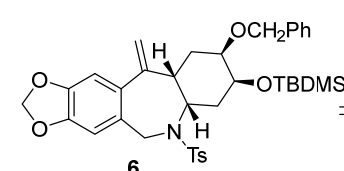

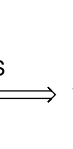

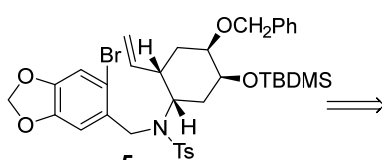

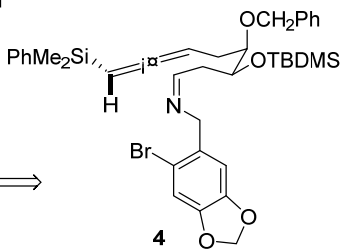

Scheme 1. The syntheses of montanine-type alkaloids

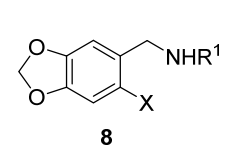

$\mathrm{X}=\mathrm{H}, \mathrm{Br}, \mathrm{I}$ $\mathrm{R}^{1}=\mathrm{Ts}, \mathrm{Ms}, 2-\mathrm{Ns}$

TFA, Boc

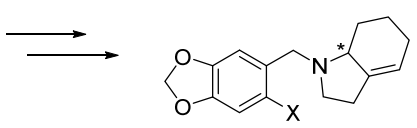

$[\mathrm{Pd}] / \mathrm{BOP}$ Ligands
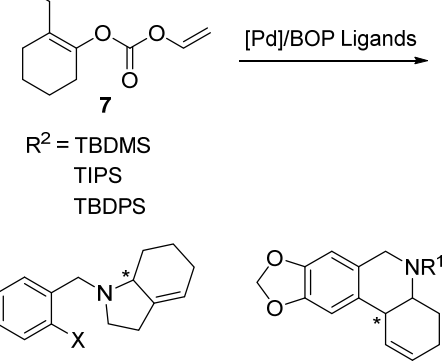

fused polycyclic alkaloids

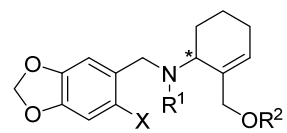

cyclohexenylcatecholamides

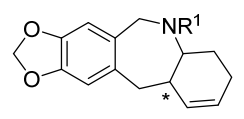

4 O

Scheme 2. Pd-catalyzed AAA reactions for the syntheses of fused polycyclic alkaloids

First, the evaluation of allylic substrates 7a-c was performed using BOP ligand (S)-L1c and nucleophile 8a (1.1 equiv.) under conditions similar to those used for the successful intermolecular Pd-catalyzed AAE reaction recently reported. ${ }^{32}$ Thus, the reactions were carried out in DMF at $0.1 \mathrm{M}$ substrate concentration with a $\operatorname{Pd}(\mathrm{II}) /(S)-\mathrm{L1c}$ ratio of $1: 1.5$. The results are shown in Table 1 . The AAA reaction proceeded as anticipated for $7 \mathbf{a}$ and $7 \mathbf{b}$ to give the corresponding cyclohexenylamides $(S)-10 x$ and $(S)-10 a$ in good yields and enantiopurity (entries 1 and 2). However, no AAA reaction took place when $7 \mathbf{c}$ was used as the substrate under the same conditions (Table 1 , entry 3 ). The result indicates that the TBDPS group is too bulky for the $\pi$-allylic-Pd species generated to accept a nucleophilic attack of piperonylamides 8a. It is worthy of note that $7 \mathbf{c}$ gave the best result in the AAE reaction. ${ }^{32}$ Thus, the results have revealed that the nature of nucleophiles plays a critical role in asymmetric allylic substitution reactions. The reactions also yielded cyclohexadiene side products 11x and 11a (entries 1 and 2). Since it is easy to separate non-polar side product $\mathbf{1 1}$ by flash chromatography, it is not important for this AAA process, especially when $\mathbf{8}$ is used as the limiting reactant. Nevertheless, this side reaction can be used for selection of reaction variables for optimization. Based on the results, allylic carbonate $\mathbf{7 b}$ was naturally selected for further study.
Table 1. Evaluation of $7 \mathrm{a}-\mathrm{c}$ in the reaction with $8 \mathrm{a}$

\begin{tabular}{|c|c|c|c|c|c|}
\hline $\begin{array}{c}\mathbf{8 a} \\
(1.1 \text { eq. })\end{array}$ & $\begin{array}{l}\text { 7a } R \\
7 \mathrm{~b} R \\
7 \mathrm{c} R\end{array}$ & $\begin{array}{l}\text { IPS } \\
\text { BDMS } \\
\text { BDPS }\end{array}$ & & & $\begin{array}{l}11 \mathrm{x} \\
11 \mathrm{a}\end{array}$ \\
\hline entry & substrate & $\begin{array}{c}\text { conversion }^{a} \\
(\%)\end{array}$ & $(S)-\mathbf{1 0}^{b}(\%$ ee $)$ & 10:11 & \\
\hline 1 & $7 a$ & $>95 \%$ & 82 & $72: 28$ & \\
\hline 2 & $7 b$ & $>95 \%$ & 85 & $85: 15$ & \\
\hline 3 & $7 c$ & $--^{c}$ & $--^{c}$ & -- & \\
\hline
\end{tabular}

${ }^{a}$ Determined by ${ }^{1} \mathrm{H}$ NMR. ${ }^{b}$ Determined by HPLC using Chiralcel ODH. ${ }^{c} \mathbf{7 c}$ was consumed, but no reaction with $\mathbf{8 a}$.

Next, several BOP ligands (Scheme 2) were evaluated for the reaction of $\mathbf{7 b}$ with $\mathbf{8 a}$ using DMF as the solvent at room temperature for $24 \mathrm{~h}$. The results are summarized in Table 2. All reactions completed in $24 \mathrm{~h}$. The entry 0 shows the result using (S)-L1c from Table 1 for comparison. BOP ligand (S)-L1a bearing a benzyl group at the 3,3'-positions gave (S)-10a with $80 \%$ ee (entry 1). The introduction of a bulky substituent at the meta position, i.e., 3,5-di-tert-butylbenzyl groups at the 3,3'-positions of the biphenyl moiety, i.e., (S)-L1b, slightly improved the 
enantioselectivity (entry 2). The use of 2,4,6-trimethylbenzyl groups at the 3,3;-positions and 3,5-dimethylphenyl groups on phosphorus, i.e., (S)-L2c, substantially increased the enantioselectivity to $93 \%$ ee (entry 3 ). Although (S)-L1a gave the best product selectivity, we selected $(S)$-L2c for further study, simply because it gave the best enantioselectivity.

Table 2. Evaluation of BOP ligands for the reaction of $7 \mathrm{~b}$ with $8 \mathbf{a}^{a}$

\begin{tabular}{ccccc}
\hline entry & ligand & $\begin{array}{c}\text { conversion }^{b} \\
(\%)\end{array}$ & $\begin{array}{c}(S)-\mathbf{1 0 a}^{c} \\
(\% \text { ee })\end{array}$ & 10a:11a \\
\hline 0 & (S)-L1c & $>95 \%$ & 85 & $85: 15$ \\
1 & (S)-L1a & $>95 \%$ & 80 & $91: 9$ \\
2 & $(S)-L 1 b$ & $>95 \%$ & 83 & $85: 15$ \\
3 & $(S)-L 2 c$ & $>95 \%$ & 93 & $73: 27$ \\
\hline
\end{tabular}

${ }^{a}$ Reactions were run using $7 \mathbf{b}(0.1 \mathrm{M}), \mathbf{8 a}\left(1.1\right.$ equiv.), $[\mathrm{Pd}(\text { allyl }) \mathrm{Cl}]_{2}(2.5 \mathrm{~mol}$ $\%$ ) with a BOP ligand $(7.5 \mathrm{~mol} \%)$ in DMF at room temperature $\left(25^{\circ} \mathrm{C}\right)$ for 24 h. ${ }^{b, c}$ See footnotes of Table 1 .

Next, we examined the effects of Pd catalyst precursors, reaction temperature and the concentration of reactants. Results are summarized in Table 3 . We examined the efficiency of $\operatorname{Pd}(0)$ catalyst precursor, i.e., $\mathrm{Pd}_{2}(\mathrm{dba})_{3}$, as compared to $\mathrm{Pd}(\mathrm{II})$ complex, $[\mathrm{Pd}(\text { allyl }) \mathrm{Cl}]_{2}$. The reaction using the $\mathrm{Pd}(0)$ complex gave the same enantioselectivity as that with the $\mathrm{Pd}(\mathrm{II})$ complex, but the product selectivity was higher (entry 1 ). The same reaction run at $0{ }^{\circ} \mathrm{C}$ increased the enantioselectivity to $95 \%$ ee with further improved product selectivity, but the reaction was slowed as anticipated (entry 2). The reduction in the catalyst loading from $2.5 \mathrm{~mol} \%$ to $1.0 \mathrm{~mol} \%$ in the reaction at $25{ }^{\circ} \mathrm{C}$ did not affect the enantioselectivity, but the product selectivity was somewhat lowered (entry 3 ). Increase in the substrate concentration from 0.1 $\mathrm{M}$ to $0.2 \mathrm{M}$ significantly accelerated the reaction by keeping excellent enantioselectivity $(95 \%$ ee) (entry 4). Although $\mathrm{Pd}_{2}(\mathrm{dba})_{3}$ appeared to serve as excellent Pd catalyst precursor, dibenzylideneacetone (dba) released to the reaction mixture happened to have almost the same Rf value as that of the product $\mathbf{1 0 a}$, and thus rather difficult to separate by chromatography. Accordingly, we switched back to $[\mathrm{Pd}(\text { allyl }) \mathrm{Cl}]_{2}$ under the optimized conditions, i.e., $0.2 \mathrm{M}$ substrate concentration with 1.0 mole \% of the Pd catalyst precursor. Then, it was found that the $\operatorname{Pd}(\mathrm{II})$ precursor gave essentially the same results, i.e. full conversion and $95 \%$ ee, as those for the $\operatorname{Pd}(0)$ precursor (entry 5 ). Thus, $[\mathrm{Pd}(\text { allyl }) \mathrm{Cl}]_{2}$ was used as the Pd catalyst precursor for further study.

Table 3. Effect of Pd catalyst precursors and reaction variables

\begin{tabular}{|c|c|c|c|c|c|}
\hline $\begin{array}{r}8 \mathbf{a} \\
(1.1 \mathrm{e} \\
\end{array}$ & 7 & & TBDMS & 10a & $11 a$ \\
\hline entry & $\begin{array}{l}\text { catalyst } \\
(\mathrm{mol} \%)\end{array}$ & $\begin{array}{l}\text { temp. } \\
\left({ }^{\circ} \mathrm{C}\right)\end{array}$ & $\begin{array}{c}\text { conversion }^{a} \\
(\%)\end{array}$ & $\begin{array}{c}10 \mathbf{a}^{b} \\
(\% \text { ee })\end{array}$ & 10a:11a \\
\hline $1^{c}$ & $\begin{array}{l}\mathrm{Pd}_{2}(\mathrm{dba})_{3} \\
\quad(2.5)\end{array}$ & 25 & $>95$ & 93 & $79: 21$ \\
\hline $2^{c}$ & $\begin{array}{l}\mathrm{Pd}_{2}(\mathrm{dba})_{3} \\
\quad(2.5)\end{array}$ & 0 & 66 & 95 & $86: 14$ \\
\hline $3^{d}$ & $\begin{array}{l}\mathrm{Pd}_{2}(\mathrm{dba})_{3} \\
\quad(1.0)\end{array}$ & 25 & 68 & 95 & $75: 25$ \\
\hline $4^{d, e}$ & $\begin{array}{c}\mathrm{Pd}_{2}(\mathrm{dba})_{3} \\
(1.0)\end{array}$ & 25 & $>95$ & 95 & $75: 25$ \\
\hline $5^{d, e}$ & $\begin{array}{c}{[\mathrm{Pd}(\text { allyl }) \mathrm{Cl}]_{2}} \\
(1,0)\end{array}$ & 25 & $>95$ & 95 & $73: 27$ \\
\hline
\end{tabular}

${ }^{a, b}$ See the footnotes of Table $1 .{ }^{c}$ At $0.1 \mathrm{M}$ concentration. ${ }^{d} 1 \mathrm{~mol} \%$ of Pd complex and $3 \mathrm{~mol} \%$ of BOP ligands. ${ }^{e}$ At $0.2 \mathrm{M}$ concentration.
Finally, we examined the effects of $N$-protecting groups of piperonylamides $\mathbf{8}$ on the enantioselectivity and reactivity in this AAA reaction under the optimized conditions described above. We used tosyl, 2-nosyl, mesyl, trifluoroacetyl and $t$-Boc as the $N$ protecting groups. Results are summarized in Table 4. The reactions with 8 bearing $N$-sulfonyl groups, i.e., $8 \mathbf{a}, \mathbf{8 b}$ and $\mathbf{8 c}$, exhibited high reactivity and enantioselectivity (entries 1-3), although the use of mesyl, a smaller sulfonyl group, somewhat lowered enantioselectivity to $90 \%$ ee (entry 3 ). In contrast, attempted reactions with $\mathbf{8 d}$ bearing a trifluoroacetyl group and $\mathbf{8 e}$ bearing a $t$-Boc group did not yield the corresponding AAA products al all (entries 4 and 5).

In addition to 2-bromopiperonylsulfonamides 8a-c, pipeconylsulfonamide $8 \mathbf{f}$ was also employed as a nucleophile in this AAA reaction (entry 6). The reaction gave the corresponding product $\mathbf{1 0 f}$ with $93 \%$ ee.

Table 4. Effects of $N$-protecting groups of 8 on the AAA reaction

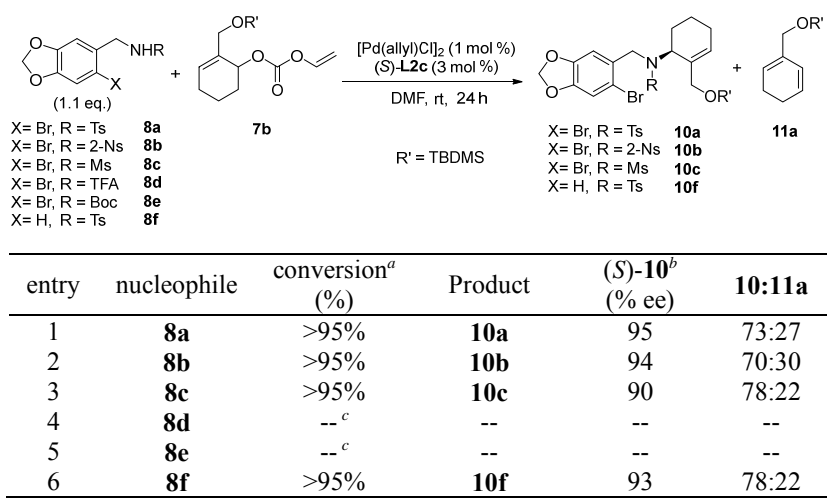

${ }^{a, b}$ See footnotes of Table 1. ${ }^{c} \mathbf{7 b}$ was consumed, but no reaction with $8 \mathbf{d}$ or $8 \mathbf{e}$.

Although both $\mathbf{8 a}$ and $\mathbf{8 b}$ were found to be excellent nucleophiles in this AAA reaction, yielding 10a and $\mathbf{1 0 b}$, respectively, with excellent enantiopurity, a nosyl $\mathrm{N}$-protecting group has an advantage for certain functional group manipulations, due to its easier removal than an $N$-tosyl group. ${ }^{33}$ Accordingly, we decided to prepare $(S)-\mathbf{1 0 b}$ in a multi-gram scale and use it for the synthesis of a couple of fused polycyclic alkaloids.

The asymmetric synthesis of (S)-10b was carried out using 1.4 equivalents of $\mathbf{7 b}$ with $\mathbf{8 b}$ in the presence of $[\mathrm{Pd}(\text { allyl }) \mathrm{Cl}]_{2}(1.0$ mol\%) and (S)-L2c $(3 \mathrm{~mol} \%)$ at $25{ }^{\circ} \mathrm{C}$ in DMF for $24 \mathrm{~h}$. The reaction gave (S)-10b in $96 \%$ isolated yield (based on $\mathbf{8 b}$ ) and $94 \%$ ee (Scheme 3). The removal of 11a was very easy as mentioned above. In the same manner, $(S)$-10f was obtained in $94 \%$ yield and $93 \%$ ee.

Cyclohexenylpiperonylamide (S)-10b (94\% ee), thus obtained, was converted to a fused tetracyclic alkaloid $\mathbf{1 8}$ and an indoline alkaloid 19, as illustrated in Scheme 3. Nitrile (S)-14 was obtained in excellent yield for 2 steps from $(S)$-10b via $(S)-\mathbf{1 3 b}$ alcohol using a Mitsunobu reaction. The attempted Pd-catalyzed intramolecular Heck reaction of $(S)-\mathbf{1 4}$ under the standard conditions did not proceed at all. We reasoned that this would be due to the bulkiness of the nosyl group. Thus, nitrile $(S)-\mathbf{1 6}$, bearing a smaller tifluoroacetyl group, was prepared by the simple deprotection and protection of (S)-14 and subjected to an intramolecular Heck reaction. Indeed the reaction gave tetracyclic $(-)-17$ in $58 \%$ yield, which was deprotected to afford fused tetracyclic alkaloid (-)-18 in excellent yield. The relative stereochemistry of (-)-18 was determined by NOESY. 
Indoline alkaloid (S)-19 with a 2-bromopiperonyl group was synthesized from $(S)-\mathbf{1 5}$ via reduction of nitrile, followed by reductive amination in fairy good yield for two steps (Scheme 3).

Another fused tetracyclic alkaloid (S)-21 bearing a benzazephine skeleton was synthesized starting from $(S)-\mathbf{1 0 f}(93 \%$ ee). This synthesis features $\mathrm{Zn}(\mathrm{II})$-promoted intramolecular Friedel-Crafts reaction of bromide $(S)$-20, which was prepared from (S)-10f in two steps (Scheme 3). It is noteworthy that common Lewis acids for Friedel-Craft reactions, such as $\mathrm{AlCl}_{3}$, $\mathrm{InBr}_{3}, \mathrm{SnCl}_{4}, \mathrm{TiCl}_{4}$, etc. only yielded messy reactions.
In summary, cyclohexenylpiperonylamides $\mathbf{1 0}$ with excellent enantiopurity (93-95\% ee) were obtained in high yields through the AAA reaction of piperonylamides 8 with $7 \mathbf{b}$ using BOP ligand $(S)$-L2c. These amides $(S)-\mathbf{1 0 b}(94 \%$ ee) and $(S)-\mathbf{1 0 f}(93 \%$ ee) were converted to fused polycyclic alkaloids,(-)-18, (S)-19 and (S)-21, in a short sequence of steps. Further transformations of these fused polycyclic alkaloids to amarylidaceae alkaloids are currently underway in our laboratory.

\section{Acknowledgments}

This work was supported by a grant from the National Science Foundation.
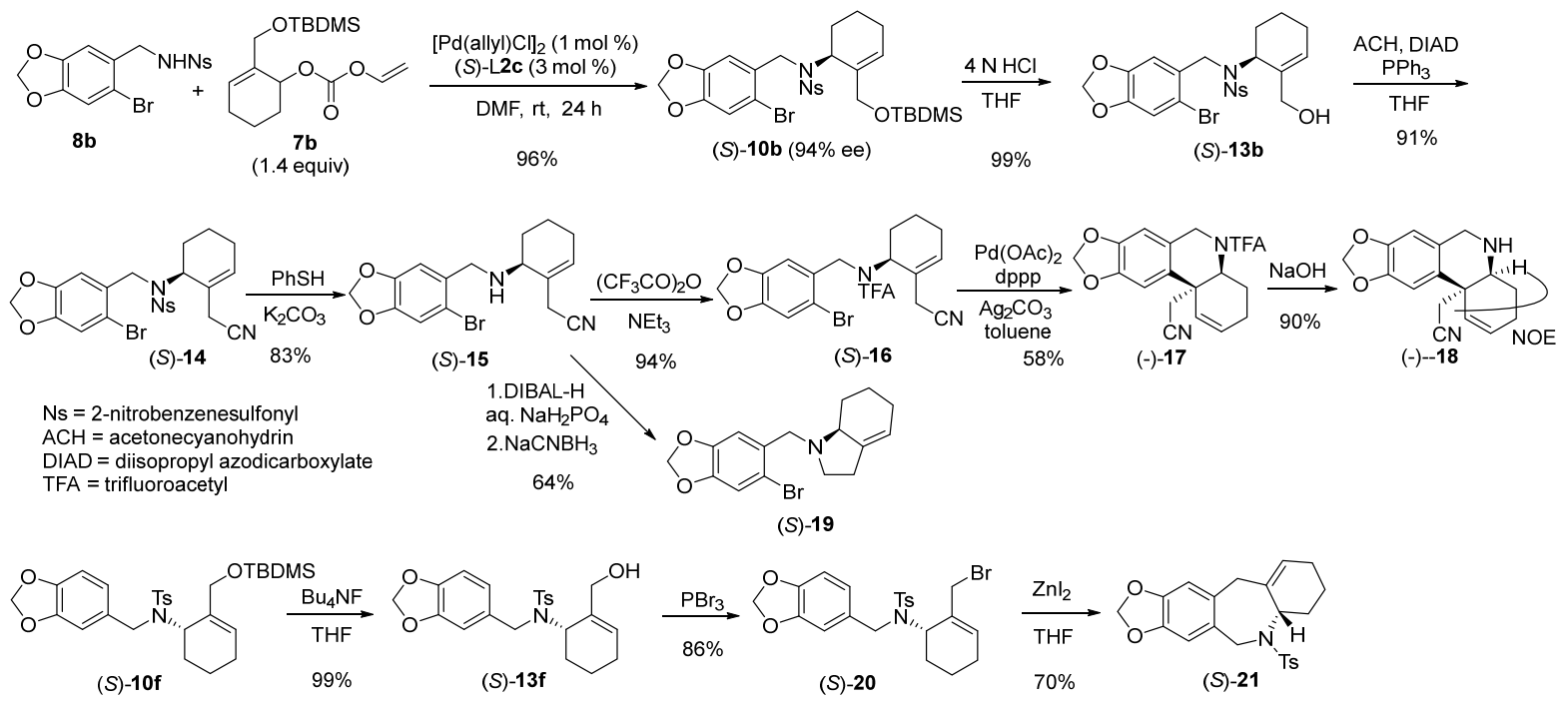

Scheme 3. Syntheses of polycyclic alkaloids 18, 19 and 21

\section{Supplementary data}

Supplementary data (experimental procedures and analytical data for all the new compounds with ${ }^{1} \mathrm{H}$ and ${ }^{13} \mathrm{C}$ NMR spectra) associated with this article can be found, in the online version, XXXXXXXXXXXXXXXXxx.

\section{References and notes}

1. Jin, Z. Nat. Prod. Rep. 2007, 24, 886.

2. McNulty, J.; Nair, J. J.; Codina, C.; Bastida, J.; Pandey, S.; Gerasimoff, J.; Griffin, C. Phytochemistry 2007, 68, 1068.

3. Griffin, C.; Sharda, N.; Sood, D.; Nair, J. J.; McNulty, J.; Pandey, S. Cancer Cell Int. 2007, 7, 10.

4. Liu, J.; Li, Y.; Tang, L. J.; Zhang, G. P.; Hu, W. X. Biomed. Pharmacother. 2007, 61, 229.

5. Schurmann da Silva A. F.; de Andrade, J. P.; Bevilaqua, L. R. M.; de Souza, M. M.; Izquierdo, I.; Henriques, A. T.; Zuanazzi, J. A. S. Pharm., Biochem. Behav. 2006, 85, 148.

6. Lewis, J. R. Nat. Prod. Rep. 2000, 17, 57.

7. Pettit, G. R.; Pettit III, G. R.; Backhaus, R. A.; Boyd, M. R.; Meerow, A. W. J. Nat. Prod. 1993, 56, 1682.

8. Kornienko, A.; Evidente, A. Chem. Rev. 2008, 108, 1982.

9. Ingrassia, L.; Lefranc, F.; Mathieu, V.; Darro, F.; Kiss, R. Transl. Oncol. 2008, 1,1 .

10. Ingrassia, L.; Lefranc, F.; Dewelle, J.; Pottier, L.; Mathieu, V.; SpieglKreinecker, S.; Sauvage, S.; El Yazidi, M.; Dehoux, M.; Berger, W.; Van Quaquebeke, E.; Kiss, R. J. Med. Chem. 2009, 52, 1100

11. Evidente, A.; Kornienko, A. Phytochem. Rev. 2009, 8, 449.

12. Kekre, N.; Griffin, C.; McNulty, J.; Pandey, S. Cancer Chemother. Pharmacol. 2005, 56, 29

13. Overman, L. E.; Shim, J. J. Org. Chem. 1991, 56, 5005.

14. Anada, M.; Tanaka, M.; Shimada, N.; Nambu, H.; Yamawaki, M.;
Hashimoto, S. Tetrahedron 2009, 65, 3069.

15. Jin, J.; Weinreb, S. M. J. Am. Soc. Chem. 1997, 119, 5773

16. Nishimata, T.; Sato, Y.; Mori, M. J. Org. Chem. 2004, 69, 1837.

17. Bru, C.; Guillou, C. Tetrahedron 2006, 62, 9043.

18. Tam, N. T.; Chang, J.; Jung, E.-J.; Cho, C.-G. J. Org. Chem. 2008, 73, 6258.

19. Pandey, G.; Murugan, A.; Balakrishnan, M. Chem. Commun. 2002, 624

20. Doyle, T. J.; Hendrix, M.; VanDerveer, D.; Javanmard, S.; Haseltine, J. Tetrahedron 1997, 53, 11153.

21. Banwell, M. G.; Kokas, O. J.; Willis, A. C. Org. Lett. 2007, 9, 3503.

22. Yamada, K.; Yamashita. M.; Sumiyoshi, T.; Nishimura, K.; Tomioka, K. Org. Lett. 2009, 11, 1631

23. Bao, X.; Cao, Y.-X.; Chu, W.-D.; Qu, H.; Du, J.-Y.; Zhao, X.-H.; Ma, X.-Y.; Wang, C.-T.; Fan, C.-A. Angew., Chem., Int. Ed. 2013, 52, 14167.

24. Nemoto, T.; Masuda, T.; Akimoto, Y.; Fukuyama, T.; Hamada, Y. Org. Lett. 2005, 7, 4447

25. Hua, Z.; Vassar, V. C.; Ojima, I. Org. Lett. 2003, 5, 3831.

26. Hua, Z.; Vassar, V. C.; Choi, H.; Ojima, I. Proc. Natl. Acad. Sci. U. S. A. 2004, 101, 5411 .

27. Choi, H.; Hua, Z.; Ojima, I. Org. Lett. 2004, 6, 2689.

28. Chapsal, B. D.; Hua, Z.; Ojima, I. Tetrahedron Asymmetry 2006, 17, 642.

29. Chapsal, B. D.; Ojima, I. Org. Lett. 2006, 8, 1395

30. Shi, C.; Ojima, I. Tetrahedron 2007, 63, 8563.

31. Shi, C.; Chien, C.-W.; Ojima, I. Chem. Asian J. 2011, 6, 674.

32. Lin, C.-F.; Ojima, I. J. Org. Chem. 2011, 76, 6240.

33. Chien, C.-W.; Shi, C.; Lin, C.-F.; Ojima, I. Tetrahedron 2011, 67, 6513.

34. Zang, Y.; Ojima, I. J. Org. Chem. 2013, 78, 4013.

35. Kurosawa, W.; Kan, T.; Fukuyama, T. Org. Synth. 2002, 79, 186. 


\section{Graphical Abstract}

To create your abstract, type over the instructions in the template box below.

Fonts or abstract dimensions should not be changed or altered.

Pd-Catalyzed Asymmetric Allylic Amination with BOP Ligands and Its Application to the Synthesis of Fused Polycyclic Alkaloids

Yang Zang and Iwao Ojima*

Department of Chemistry, Stony Brook University, Stony Brook, New York 11794-3400, United States

\section{Leave this area blank for abstract info.}

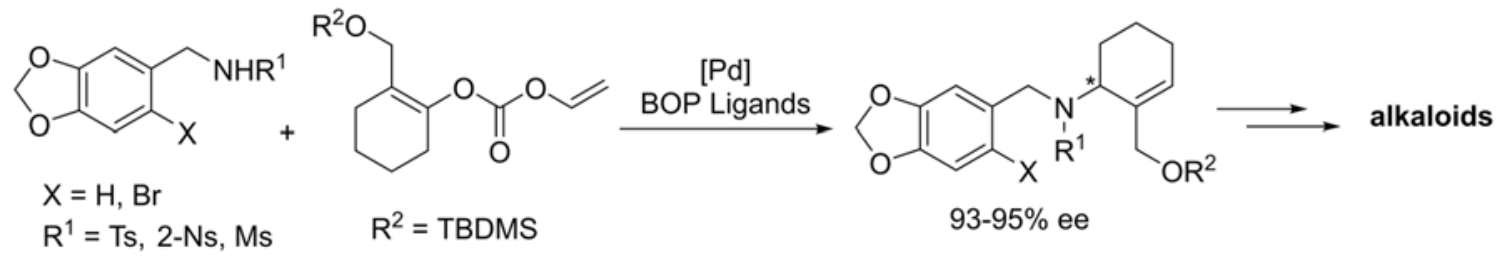

